\title{
RANCANG BANGUN GAME MONOPOLI EDUKASI DENGAN LATAR BELAKANG PENGETAHUAN ADAT ISTIADAT DI INDONESIA
}

\author{
Ekojono $^{1}$, Sofyan Noor Arif ${ }^{2}$, Denny Kharisma Putra ${ }^{3}$ \\ ${ }^{1,2}$ Teknik Informatika, Teknologi Informasi, Politeknik Negeri Malang, ${ }^{3}$ Politeknik Negeri Malang \\ 1'ekojono2000@yahoo.com, ${ }^{2}$ sofyan.89@gmail.com, ${ }^{3}$ masterdenny12@gmail.com
}

\begin{abstract}
Abstrak
Indonesia memiliki banyak kebudayaan, tradisi, dan adat istiadat yang tidak banyak diketahui oleh generasi muda. Budaya dan tradisi yang dipercaya turun temurun dan merupakan identitas bangsa harus dijaga dan dilestarikan oleh para penerus bangsa. Akan tetapi saat ini budaya di Indonesia kini sudah terkikis semua oleh yang namanya kemajuan zaman.

Berdasarkan permasalahan tersebut perlu pengembangan game Monopoli Edukasi Adat Istiadat di Indonesia menggunakan metode LCG (Linier Congruential Generator). Sistem yang dirancang dan diimplementasikan berbasis Game Engine Unity, menggunakan bahasa pemrograman C Sharp, dengan berisikan materi mengenai tarian adat, pakaian adat dan rumah adat yang ada di Indonesia. Sistem ini merupakan penggabungan dari game Monopoli dan adat istiadat di Indonesia, diharapkan dapat membantu anak-anak untuk lebih mengenal adat istiadat di Indonesia. Dengan melakukan riset tentang cara merancang dan membuat game Monopoli diharapkan game "Monopoli Adat Istiadat Indonesia" dapat menjadi media untuk pembelajaran dan mengenal lebih jauh mengenai adat istiadat di Indonesia.
\end{abstract}

Kata kunci: Adat Istiadat di Indonesia, permainan berbasis pengetahuan, pendidikan, melestarikan

\section{Pendahuluan}

\subsection{Latar Belakang}

Pada era yang maju saat ini, game adalah salah satu media teknologi yang populer di kalangan masyarakat baik dari anak kecil maupun dewasa karena game dapat menghilangkan stress dan mengisi waktu luang. Game juga merupakan bentuk aplikasi edukatif, artinya bisa dijadikan sebagai media pembelajaran dimana prosesnya bisa dilakukan dengan konsep belajar sambil bermain dengan memanfaatkan sebuah kecerdasan buatan untuk membantu para pemain dan menghalangi pemain untuk mencapai tujuan pada game tersebut. Banyak sekali penerapan game sebagai media pembelajaran terutama pada game berlatar kebudayaan misalnya adat di Indonesia.

Indonesia adalah bangsa yang majemuk, terkenal dengan keanekaragaman dan keunikannya. Terdiri dari berbagai suku bangsa, yang mendiami belasan ribu pulau. Masingmasing suku bangsa memiliki keanekaragaman budaya tersendiri. Di setiap budaya tersebut terdapat nilai-nilai sosial dan seni yang tinggi. Pada kondisi saat ini kebudayaan mulai ditinggalkan, bahkan sebagian masyarakat Indonesia malu akan kebudayaannya sebagai jati diri sebuah bangsa. Hal ini mengakibatkan hilangnya keanekaragaman budaya Indonesia secara perlahan-lahan, yang tidak terlepas dari pengaruh budaya luar dan karakter masyarakat Indonesia yang suka meniru. Bahkan seiring perkembangan zaman dan teknologi yang semakin lama semakin canggih serta perdagangan bebas yang telah terjadi di dunia khususnya Indonesia telah meracuni bangsa Indonesia terhadap moral akhlak dan tata krama pergaulan anak remaja, adat budaya Indonesia yang dulu Indonesia kaya akan budayanya kini sudah terkikis semua oleh yang namanya kemajuan zaman, salah satu contohnya yang telah kita tahu kesenian Reog Ponorogo yang berasal dari Jawa Timur Ponorogo telah di akui oleh bangsa Malaysia, hal itu disebabkan karena kurangnya kepedulian dan pelestarian

Dari permasalahan tersebut, perlu dibangun sebuah game untuk mengenalkan kepada masyarakat luas tentang adat istiadat yang ada di Indonesia yang Membahas tentang rumah adat, senjata tradisional dan tarian dengan menggunakan kategori game edukasi dengan format latar monopoli yang nantinya setiap karakter jika menempati sebuah wilayah/daerah akan terdapat soal yang terkait dengan daerah tersebut

\subsection{Rumusan Masalah}

1. Bagaimana membuat game Edukasi Monopoli dengan latarbelakang Adat Istiadat di Indonesia sebagai media alternatif agar 
masyarakat bisa mengenal adat-adat di Indonesia?

\subsection{Batasan Masalah}

1. Game ini Membahas tentang Adat Istiadat di Indonesia.

2. Implementasi pada game ini menggunakan metode LCG (Linier Continuental Generator).

3. Game ini berformat 2D

\section{Landasan Teori}

\subsection{Game Edukasi}

Game edukasi adalah salah satu jenis media yang digunakan untuk memberikan pengajaran, menambah pengetahuan penggunanya melalui suatu media unik dan menarik. Jenis ini biasanya ditujukan untuk anak-anak, maka permainan yang sangat diperlukan disini bukan tingkat kesulitan yang dipentingkan.

Berdasarkan uraian di atas maka dapat disimpulkan game Edukasi adalah salah satu bentuk game yang dapat berguna untuk menunjang proses belajar-mengajar secara lebih menyenangkan dan lebih kreatif, dan digunakan untuk memberikan pengajaran atau menambah pengetahuan penggunanya melalui suatu media yang menarik.

\subsection{Metode LCG (Linier Congruental Generator)}

Metode Linear Congruential Generator (LCG) digunakan untuk menghasilkan bilangan acak yang digunakan dalam permainan yang mengandung pengacakan seperti pengacakan pada dadu. Bilangan acak yang dihasilkan oleh Linear Congruential Generator (LCG)

1. Rumus Metode LCG :

$$
X n=(a * X n-1+b) \bmod
$$

$$
\text { Dimana : }
$$

$$
\begin{array}{ll}
\mathrm{Xn} & =\text { bilangan acak ke-n dari deretnya } \\
\mathrm{Xn}-1 & =\text { bilangan acak sebelumnya } \\
\mathrm{a} & =\text { faktor pengali } \\
\mathrm{b} & =\text { increment } \\
\mathrm{m} & =\text { modulus pembagi }
\end{array}
$$

2. LCG mempunyai periode penuh $(m-1)$ jika memenuhi syarat sebagai berikut:

- $\quad b$ relatif prima terhadap $m$.

- a - 1 dapat dibagi dengan semua faktor prima dari $\mathrm{m}$

- a - 1 adalah kelipatan 4 jika $m$ adalah kelipatan 4

- $\quad \mathrm{m}>\operatorname{maks}(\mathrm{a}, \mathrm{b}, \mathrm{X} 0)$

- $\quad a>0$

$\mathrm{b}>0$

Riki, dkk (2015).

\subsection{Adat Istiadat}

\subsubsection{Adat}

Adat adalah gagasan kebudayaan yang terdiri dari nilai-nilai kebudayaan, norma, kebiasaan, kelembagaan, dan hukum adat yang lazim dilakukan di suatu daerah.

Apabila adat ini tidak dilaksanakan akan terjadi kerancuan yang menimbulkan sanksi tak tertulis oleh masyarakat setempat terhadap pelaku yang dianggap menyimpang.

\section{Metodologi}

\subsection{Desain Penelitian}

metodologi penelitian akan dijelaskan dalam penelitian tentang game edukasi Monopoli adat istiadat. Adapun tahapannya, yaitu :

1. Concept (pengkonsepan)

2. Design (pendesignan).

3. Material collecting (pengumpulan materi)

4. Assembly (pembuatan).

5. Testing (pengujian).

6. Distribution (pendistribusian)

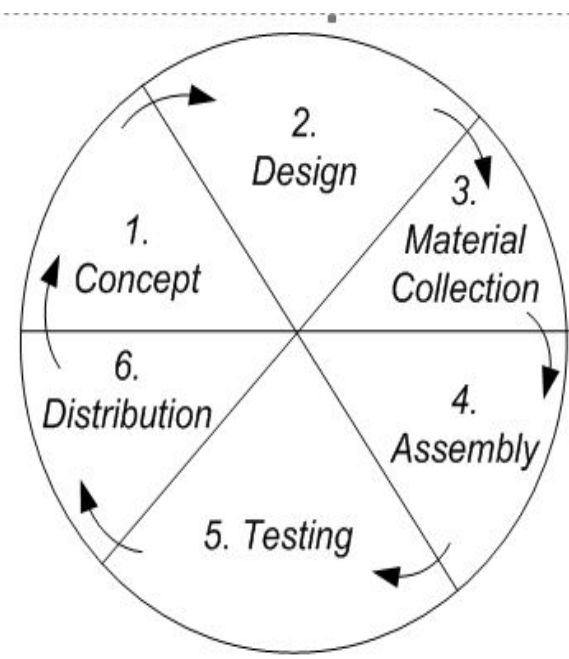

Gambar 1. Langkah-Langkah Penelitian

\section{Analisa dan Perancangan \\ 4.1 Gambaran Sistem}

Game Monopoli adat istiadat adalah game monopoli yang mengandung materi pembelajaran untuk anak SD. Materi yang disajikan dalam permainan ini meliputi adat istiadat tarian adat, rumah adat dan pakaian adat. Dimana jika player bisa menjawab pertanyaan akan mendapat bonus uang 1750. Setiap player dapat membangun rumah sesuai keinginannya dengan syarat uang mencukupi untuk membeli rumah tersebut.

Game Monopoli adat istiadat merupakan aplikasi interaktif dengan kombinasi gameplay monopoli dan pembelajaran dengan tujuan agar mempermudah daya ingat anak. Aplikasi ini bernuansa sederhana namun tetap mewakili multimedia sebagai sebuah aplikasi 
pembelajaran, yaitu dengan perpaduan teks, gambar, audio dan animasi dalam penyampaian materinya.

Pada game monopoli ini anak-anak dapat memilih menu-menu yang tersedia. Menu utama terdiri dari menu mulai, menu setting, menu materi pembelajaran dan menu keluar.

Pada menu materi pembelajaran terdapat memilih materi sesuai dengan yang diinginkan, pada menu materi terdapat tarian adat, pakaian adat dan rumah adat. Materi yang disediakan pada game nantinya akan dibuat untuk membuat pertanyaan yang ada dalam gameplay permainan

\subsubsection{Perancangan Menu}

Pada Monopoli game ini terdiri dari loading screen sebelum memasuki menu game setelah loading screen terdapat menu utama yang terdiri dari pengaturan sound, tombol play, menu pembelajaran untuk bekal menjawab pertanyaan yang ada pada game dan menu exit untuk keluar pada game.

\subsubsection{Perancangan Menu Pembelajaran}

Berikut ini merupakan perancangan menu pada aplikasi yang dibuat yaitu perancangan menu pembelajaran, berisikan materi mengenai adat istiadat di Indonesia dengan terdapat pilihan:

a. Tarian adat: Materi adat istiadat mengenai tarian adat, yang ada di Indonesia.

b. Pakain adat: Materi adat istiadat mengenai pakaian adat, yang ada di Indonesia

c. Rumah adat: Materi adat istiadat mengenai rumah adat, yang ada di Indonesia.

\subsection{Metode LCG (Linier Conquerintal Generator)}

Metode Linear Congruential Generator

(LCG) digunakan untuk menghasilkan bilangan acak yang digunakan dalam permainan yang mengandung pengacakan seperti pengacakan pada dadu. Bilangan acak yang dihasilkan oleh Linear Congruential Generator (LCG) ini akan digunakan untuk menentukan posisi dari bilangan 1 sampai n pada setiap baris

Berikut ini adalah flowchart dari Linier Conquerintal Generator:

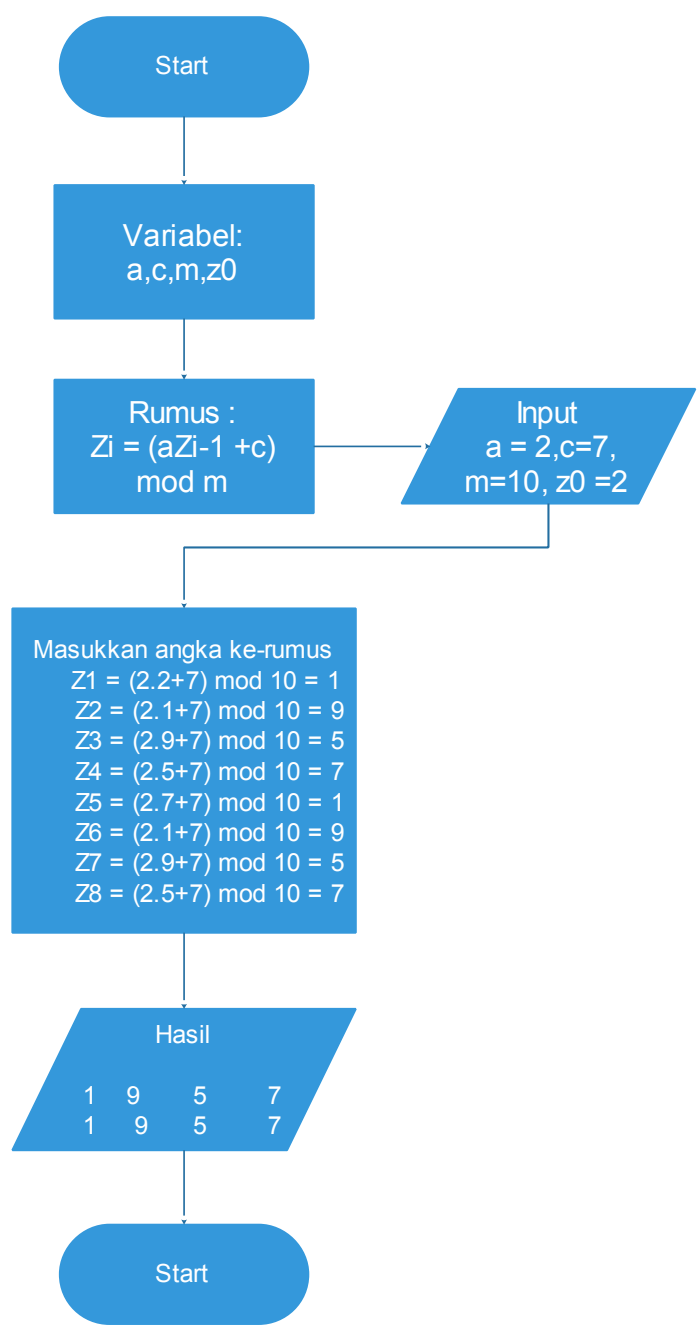

Gambar 2. Flowchart Linier Conquerintal
Generator

4.3 Perhitungan Metode

Cara penentuannya adalah sebagai berikut:

1. Bangkitkan $\mathrm{n}$ buah bilangan acak dengan menggunakan Linear Congruential Generator (LCG).

2. Urutkan bilangan acak yang dihasilkan tersebut dari kecil ke besar.

3. Urutan bilangan acak tersebut merupakan urutan nilai yang akan ditempatkan. Sebagai contoh, apabila bilangan acak yang dihasilkan adalah 14, 71, 21, 5, yang diurutkan menjadi 5, 14, 21, 71.Urutan bilangan acak yang dihasilkan adalah 4, 1,3, 2.

4. Rumus Metode LCG :

$$
\begin{aligned}
& \mathbf{X n}=(\mathbf{a} * \mathbf{X n}-\mathbf{1}+\mathbf{b}) \mathbf{m o d} \\
& \text { Dimana : } \\
& \mathrm{Xn} \quad=\text { bilangan acak ke-n dari deretnya } \\
& \mathrm{Xn}-1=\text { bilangan acak sebelumnya } \\
& \mathrm{a} \quad=\text { faktor pengali } \\
& \mathrm{b} \quad=\text { increment }
\end{aligned}
$$


$\mathrm{m}=$ modulus pembagi

5. LCG mempunyai periode penuh $(\mathrm{m}-1)$ jika memenuhi syarat sebagai berikut:

- b relatif prima terhadap $m$.

- a - 1 dapat dibagi dengan semua faktor prima dari $m$

- a - 1 adalah kelipatan 4 jika $m$ adalah kelipatan 4

- $\quad \mathrm{m}>\operatorname{maks}(\mathrm{a}, \mathrm{b}, \mathrm{X} 0)$

- $a>0$

- $b>0$

Riki, dkk (2015).

\subsubsection{Contoh LCG Dadu:}

Membangkitkan bilangan acak sebanyak 6 kali dengan $\mathrm{a}=5, \mathrm{c}=7, \mathrm{~m}=7$, dan $Z_{0}=3$

Step 1: $3=(5 * 3+7) 7=1$

Step 2: $1=(5 * 1+7) 7=5$

Step 3: $5=\left(5^{*} 5+7\right) 7=4$

Step 4: $4=\left(5^{*} 4+7\right) 7=6$

Step 5: $6=\left(5^{*} 6+7\right) 7=2$

Step 6: $2=\left(5^{*} 2+7\right) 7=3$

Bilangan acak yang dibangkitkan adalah :

$$
\begin{array}{llllll}
1 & 5 & 4 & 6 & 2 & 3
\end{array}
$$

Tidak ada pengulangan bilangan secara periodik .

\section{Contoh 2. LCG:}

Membangkitkan bilangan acak sebanyak 8 kali dengan $\mathrm{a}=4, \mathrm{c}=7, \mathrm{~m}=15$, dan $Z_{0}=3$

- $Z_{1}=(4.2+7) \bmod 15=4$

- $\quad Z_{2}=(4.4+7) \bmod 15=8$

- $\quad Z_{3}=(4.8+7) \bmod 15=9$

- $\quad Z_{4}=(4.9+7) \bmod 15=13$

- $\quad Z_{5}=(4.13+7) \bmod 15=14$

- $Z_{6}=(4.14+7) \bmod 15=3$

- $\quad Z_{7}=(4.3+7) \bmod 15=4$

- $\quad Z_{8}=(4.4+7) \bmod 15=8$

- Bilangan acak yang dibangkitkan adalah :

$$
\begin{array}{llllll}
4 & 8 & 9 & 13 & 14 & 4
\end{array}
$$

jadi tidak terjadi pengulangan secara periodik.

\section{Analisa Penelitian}

Pada pengujian metode $L C G$ penulis melakukan pengujian pada dadu yang berisikan adat istiadat di Indonesia

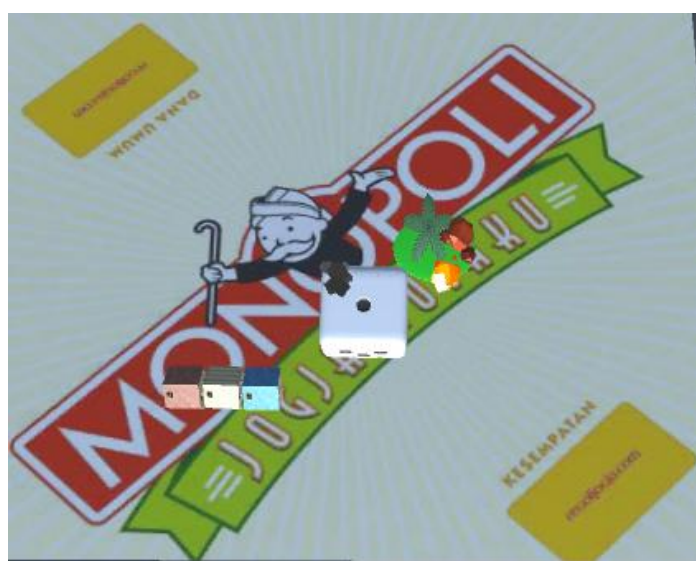

Gambar 3. Gambar Pengujian dadu

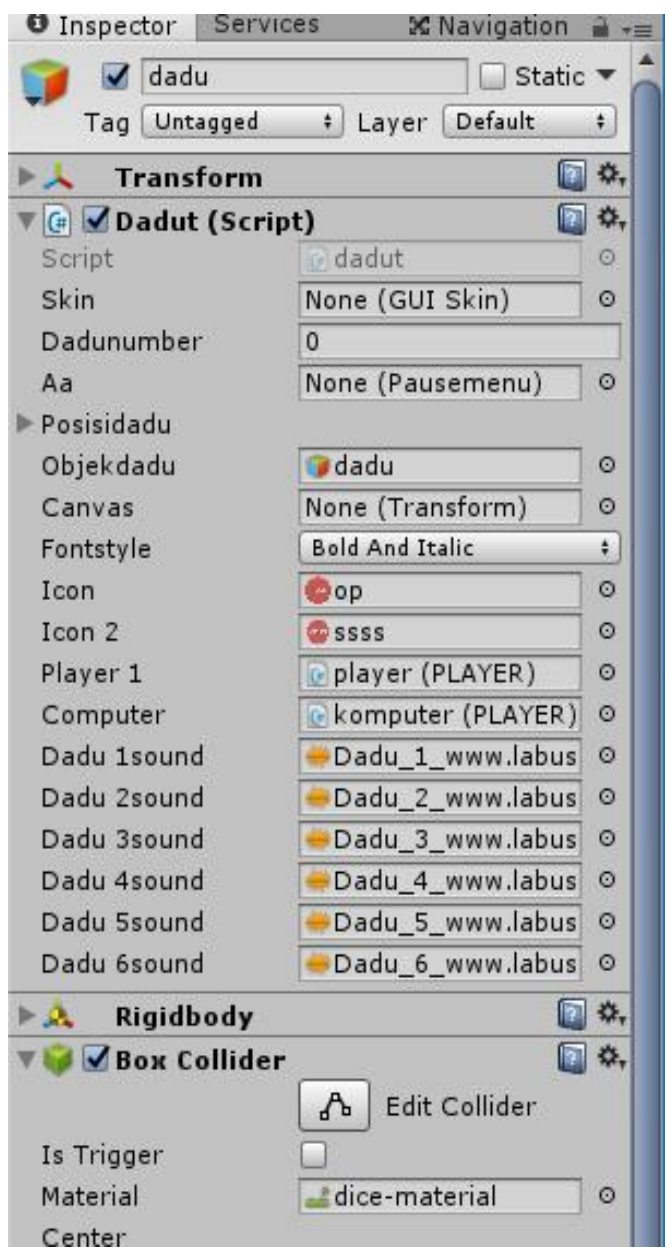

Gambar 4. Gambar Set Dadu

Implementasi coding :

void Start ()

$$
\begin{aligned}
& a=5 \\
& b=7 \\
& m=7 \\
& x=3
\end{aligned}
$$




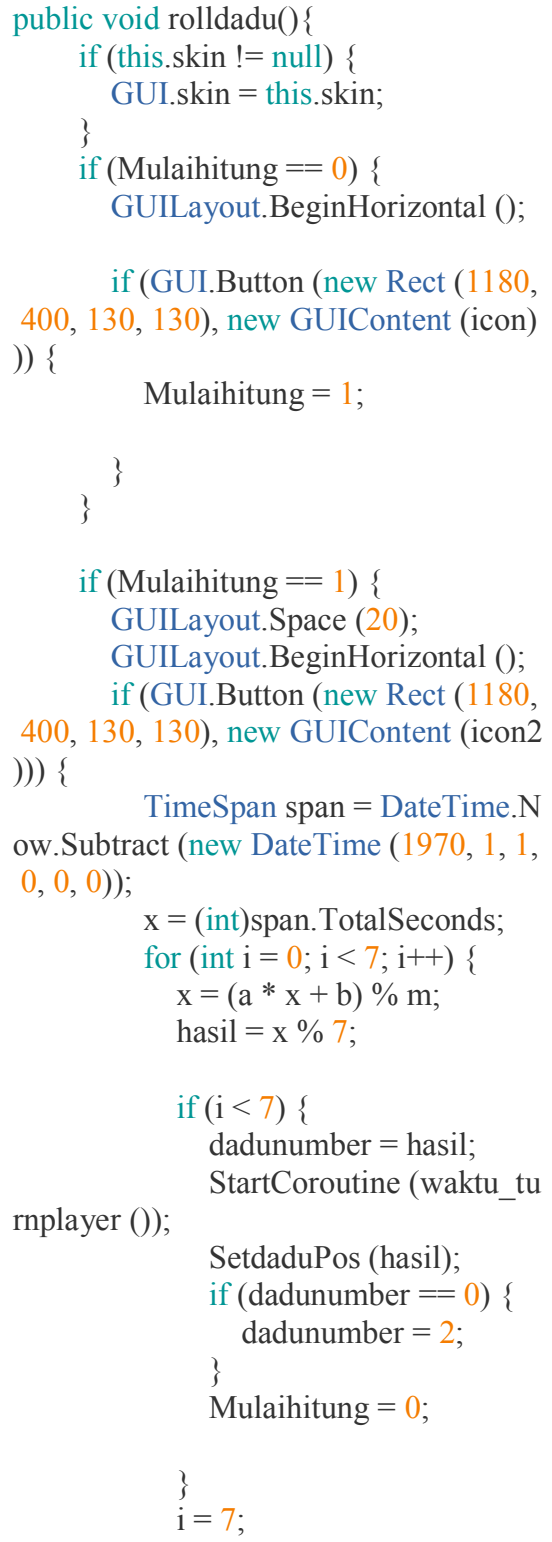

\subsection{Implementasi Soal Di Game Monopoli}

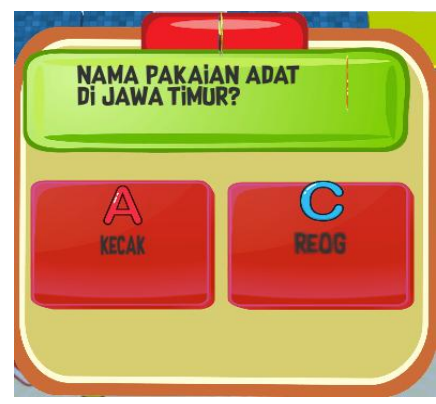

Gambar 5. Tampilan Soal
6. Implementasi Coding

void acaksoal()

Tampilsoal (hasil);

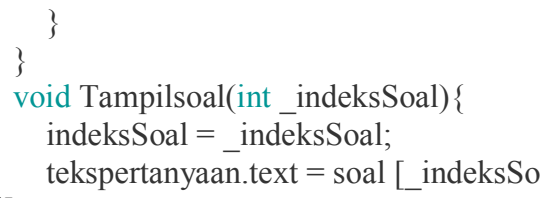

\section{Kesimpulan dan Saran}

7.1 Kesimpulan

Berdasarkan pengujian yang telah dilakukan oleh penulis pada penerapan metode $L C G$ diambil beberapa kesimpulan sebagai berikut:

1. Pada game edukasi monopoli ini metode diterapkan pada dadu, pada dadu menggunakan lcg sangat efesien dikarenakan kemunculan dadu yang keluar tidak dapat diprediksi dan selalu acak untuk setiap membuka game.

\subsection{Saran}

Saran yang diberikan untuk pengembangan sistem pada penelitian selanjutnya.

\section{Daftar Pustaka:}

Rizki Catur Putra, (2016), "Pembuatan Game Edukasi Pintar Memilih Sampah Berbasis Android'. Program Studi Informatika Fakultas Komunikasi Dan Informatika Universitas Muhammadiyah Surakarta.

Dian Wahyu Putra Dan A. Prasita Nugroho, (2016), "Game Edukasi Berbasis Android Sebagai Media Pembelajaran Untuk Anak Usia Dini". Jimp - Jurnal Informatika Merdeka Pasuruan.

Riki Wahyudi Dan Hendra Handoko Syahputra Pasaribu, (2015), "Perancangan Aplikasi Quiz Menggunakan Metode Pengacakan Linear 
Volume 4, Edisi 2, Februari 2018

Congruential Generator (Lcg) Berbasis Android'. Riau Journal Of Computer Science.

Mustofa, (2011), "Pakaian Adat Tradisional Indonesia", Azamku.Com, [Online], Available: Http://Www.Azamku.Com/Pakaian-AdatTradisional-Indonesia.

Wafda Adita Rifai, (2015), "Pengembangan Game Edukasi Lingkungan Berbasis Android", Teknik Universitas Negeri Yogyakarta.

Veinta Sonrizky Mayo, (2015), "Promosi Wisata Budaya Jawa Tengah Melalui Game Monopoli 2d Berbasis Unity", Semarang, Available: Http://Www.Azamku.Com/Pakaian-AdatTradisional-Indonesia. 